\title{
Postoperative glucocorticoid enhances recovery after endovascular aortic repair for chronic type B aortic dissection: a single- center experience
}

Mengtao $\mathrm{Wu}^{1,2+}$, Lei Zhang ${ }^{1 \dagger}$, Junmin Bao ${ }^{1 \dagger}$, Zhiqing Zhao ${ }^{1}$, Qingsheng Lu', Rui Feng ${ }^{1}$, Chao Song ${ }^{1}$, Jian Zhou ${ }^{1 *}$ and Zaiping Jing ${ }^{1 *}$

\begin{abstract}
Background: Thoracic endovascular aortic repair (TEVAR) has been chosen as a less invasive alternative for type B aortic dissections (TBADs). However, the therapeutic effect of TEVAR has been challenged by postoperative adverse events, which were induced by inflammatory response. Glucocorticoids have been widely used because of the powerful and effective anti-inflammatory properties. Nevertheless, the prognostic effect of glucocorticoids after TBAD patients underwent TEVAR remains unclear. The objective of this study was to assess the potential effect of postoperative glucocorticoids on the prognosis of TEVAR for TBADs.

Methods: A total of 92 chronic TBADs patients underwent TEVAR with epidural anesthesia between June 2012 and June 2014 was retrospectively reviewed. The patients were stratified into dexamethasone (DXM) and non-dexamethasone group (N-DXM). The indications for TEVAR were as following: malperfusion $(n=28)$; contained or impending rupture $(n=17)$; persistent intractable chest/back pain $(n=32)$; refractory hypertension $(n=15)$.

Results: No 30-day mortality and incision infection occurred in each group. The postoperative pain score on the second day was significantly higher in N-DXM group $(3.60 \pm 0.21$ versus $4.83 \pm 0.32, P=0.001)$. The differences of white blood cell, body temperature and heart rate were pronounced in both groups judged by the peak values $\left(13.01 \pm 0.58 \times 10^{9} / \mathrm{L}\right.$ versus $10.04 \pm 0.61 \times 10^{9} / \mathrm{L}, 37.67 \pm 0.08{ }^{\circ} \mathrm{C}$ versus $37.92 \pm 0.09^{\circ} \mathrm{C}$ and $89.06 \pm 1.21 \mathrm{bpm}$ versus $95.95 \pm 1.70 \mathrm{bpm}, P=0.002,0.04$ and 0.001 , respectively). The white blood cells in DXM group significantly increased on the second and third postoperative day $(P=0.009$ and 0.023$)$, while the body temperature and heart rate showed an apparent decline on the second $(P=0.001$ and 0.028$)$, third $(P=0.007$ and 0.005$)$ and fourth postoperative days $(P=0.024$ and 0.018$)$. However, the changes of false lumen volumes and the endoleak incidence at 3-month follow-up were comparable in the two groups. No significant difference of post-implantation syndrome was observed either.

Conclusions: Although postoperative prophylactic glucocorticoids administration was unable to influence mortality, incision infection or the change of false lumen volumes, it enabled to enhance the recovery of vital signs and alleviate the postoperative pain. A prospective, randomized controlled trial has been registered (NCT02523300), which will be warranted before prophylactic administration of glucocorticoids after TEVAR procedure could be recommended in the clinical work.
\end{abstract}

Keywords: Aortic dissection, Endovascular repair, Prognosis, Glucocorticoid

\footnotetext{
*Correspondence: zhoujian1-2@163.com; xueguanky@163.com

${ }^{\dagger}$ Equal contributors

${ }^{1}$ Department of Vascular Surgery, Changhai Hospital, Second Military Medical

University, 168 Changhai Road, Shanghai 200433, China

Full list of author information is available at the end of the article
} 


\section{Background}

Owing to the lower risks of mortality and morbidity compared with traditional open surgery, thoracic endovascular aortic repair (TEVAR) has been chosen as a less invasive alternative for the treatment of type $B$ aortic dissections (TBADs) in recent years [1-3]. However, the therapeutic effect of TEVAR has partly been challenged by the postoperative adverse events, which might result in disability or death [4]. The postoperative inflammatory response between stent graft and vascular wall, usually contributing to the post-implantation syndrome [5, 6], might be responsible for these adverse events [7]. But there is no consensus on how to prevent or treat the post-implantation syndrome after chronic TBAD patients underwent TEVAR until now.

Glucocorticoids have been widely used in the clinical practice by reason of the powerful and effective antiinflammatory properties [8, 9]. Previous studies had demonstrated perioperative administration of glucocorticoids had a favorable effect on the prognosis in liver resection, abdominal surgery, hip and knee surgery, etc. [10-12]. It is worth noted that long-term and high-dose using glucocorticoids would induce adverse effects [13]. Thus, the present study sought to evaluate the clinical outcomes of short-term and low-dose prophylactic administration of glucocorticoids in chronic TBADs patients after TEVAR and elucidate the potential mechanisms involved in.

\section{Methods}

\section{Study population}

The study protocol complied with the declaration of Helsinki, and was approved by the Ethics Committee of Shanghai Changhai hospital. After written informed consent forms for operations were provided, a total of 306 consecutive TBADs patients underwent TEVAR from June 2012 to June 2014. The diagnosis of TBADs was confirmed by computed tomography angiography (CTA) on a 64-slice CT scanner (Siemens, Munich, Germany) in all patients. The inclusion criteria of our study were as following: 1) chronic TBADs; 2) intervention with epidural anesthesia. The exclusion criteria were acute TBADs, intervention with general anesthesia, using antiinflammatory drugs, any trauma before TEVAR within 2 months, history of endoprosthesis implantation, history of any autoimmune disease, any type of malignancy, conservative treatment, and imcomplete data of temperature, heart rate, or white blood cell.

It should be noted that no guideline about the usage of glucocorticoids after TBAD patients underwent TEVAR was available at present. Previous studies proposed the administration of steroids could be used to reduce host biological responses in the care of post-TEVAR patients $[14,15]$. On the other hand, Ker et al. demonstrated that longer fever duration was statistically associated with longer stent grafts implanted [16]. Therefore, the short-term and low-dose glucocorticoids were regularly given to prevent longer fever duration and alleviate host immune response for the patients with more than $200 \mathrm{~mm}$ stent grafts coverage in our center.

After reviewing the medical records, the patients were stratified into two groups: 1) the dexamethasone group (DXM), patients were prophylactically given dexamethasone (5 mg/day, intravenously) on the operation day for 3 days. Then indomethacin enteric-coated tablets (p.o., $50 \mathrm{mg} /$ day) were prescribed at the end of the fasting state; 2) the non-dexamethasone group (N-DXM), patients were only given indomethacin (p.o., $50 \mathrm{mg} /$ day) at the end of the fasting state. The second generation of cephalosporin was prophylactically given in all patients before operation within $30 \mathrm{~min}$, and continuous blood pressure surveillance was conducted to maintain systolic blood pressure 100-120 mmHg after operation [17].

\section{Protocol for TEVAR procedure}

All the procedures were performed in the digital subtraction angiography suite. A standard percutaneous puncture of the access artery was performed, and heparin was given intra-arterially $(80 \mathrm{U} / \mathrm{kg})$. Angiography was routinely used to identify the true lumen and primary entry tear, followed by selective catheterization of the target vessel. A stiff wire was then placed, entering into the true lumen, following which the stent grafts were advanced and deployed consecutively to cover the primary entry tear. Four stent graft systems were used in the procedures: Zenith TX2 (COOK Medical, Bloomington, IN); TAG (W. L. Gore \& Associates, Flagstaff, AZ); Valiant (Medtronic, Minneapolis, MN) and Hercules-T (MicroPort, Shanghai, China) (Additional file 1: Table S1). Cerebrospinal fluid drainage was used when longsegment aortic coverage was planned. A vascular closure device was used to manage the access site after intervention. No post-deployment ballooning was used.

\section{Data collections}

The demographics and clinical characteristics including body temperature, heart rate, white blood cell, hemoglobin, platelet, fibrinogen, activated partial thromboplastin time and prothrombin time were retrospectively collected. The date on the preoperative day and the initial 5 days after intervention were extracted and analyzed. The peak and valley values were defined as the highest and lowest values during the period of data collection.

The intensity of postoperative acute chest/back pain was assessed by another physician blinded to the study using the visual analog scale [18] at every morning until discharged from hospital. Pain scores on the second day were used to analysis. 
CTA examinations were postoperatively arranged in all patients at 1 - and 3-month follow-up point. Parameters were obtained with the help of dedicated three-dimensional workstation (Aquarius WS 3.7.0.13, TeraRecon Inc, San Mateo, Calif). Briefly, enhanced aortic lumen was reconstructed by volume rendering technique. Then the aortic segment where thrombosis of the false lumen exists was extracted by cropping area of interest. Volume measurements were automatically done using the "volume measure" function. The new-onset thrombosis volume in false lumen was defined as the reduced volume of aorta between the preoperative and postoperative aortic volume at the same segment.
Definitions of post-implantation syndrome and the postoperative adverse events

Patient was diagnosed with post-implantation syndrome when the signs and laboratory tests met at least two items of the diagnostic criteria of the systemic inflammatory response syndrome. Judged by the peak values of white blood cell, body temperature and heart rate within the initial 5 days after intervention, patients were evaluated with a score of 2 or 3 depending on the number of systemic inflammatory response syndrome criteria presented.

The postoperative adverse events included cardiac events (myocardial infarction or arrhythmia), cerebrovascular events (cerebral infarction or hemorrhage), incision infection and 30-day mortality.



Fig. 1 Flow diagram of included patients. DXM dexamethasone group, N-DXM non-dexamethasone group, TBAD stanford type B aortic dissection, TEVAR thoracic endovascular aortic repair 
Table 1 Demographics of all patients

\begin{tabular}{llll}
\hline Variables & DXM $(n=52)$ & $\mathrm{N}-\mathrm{DXM}(n=40)$ & $P$ \\
\hline Demographic characteristics & & & \\
Age of onset, years & $58.48 \pm 1.85$ & $58.74 \pm 1.82$ & 0.921 \\
Male, $n$ (\%) & $42(80.8)$ & $33(82.5)$ & 0.832 \\
Body mass index, Kg/m ${ }^{2}$ & $24.17 \pm 0.59$ & $24.43 \pm 0.81$ & 0.806 \\
Mean arterial pressure, mmHg & $105.76 \pm 1.99$ & $102.76 \pm 3.11$ & 0.397 \\
Medical history & & & \\
Smoking, $n$ (\%) & $20(38.5)$ & $8(20.0)$ & 0.056 \\
Cerebral disease, $n(\%)$ & $2(3.8)$ & $4(10.0)$ & 0.236 \\
Coronary artery disease, $n(\%)$ & $4(7.7)$ & $2(5.0)$ & 0.604 \\
Type II diabetes, $n(\%)$ & $1(1.9)$ & $4(10.0)$ & 0.090 \\
Hypertension class, $n(\%)$ & & & 0.981 \\
1 & $4(7.7)$ & $4(10.0)$ & \\
2 & $9(17.3)$ & $7(17.5)$ & \\
3 & $29(55.8)$ & $22(55.0)$ & \\
ASA class, $n$ (\%) & & & 0.968 \\
I & $2(3.8)$ & $1(2.5)$ & \\
II & $32(61.6)$ & $26(65.0)$ & \\
III & $17(32.7)$ & $12(30.0)$ & \\
IV & $1(1.9)$ & $1(2.5)$ & \\
\hline DXM dexame & &
\end{tabular}

DXM dexamethasone group, $N$-DXM non-dexamethasone group

\section{Statistical analysis}

All analyses were performed using IBM SPSS 20.0 (IBM Corp., Armonk, NY, USA). The values were expressed as numbers, percentages, means \pm standard error or interquartile range. Categorical variables were compared using chi-squared or Fisher's exact test, and a two-group t-test or the nonparametric Mann-Whitney $U$ test was used to compare the continuous variables. The probability values were two-tailed and the null hypothesis was rejected for values of $P<0.05$.

Table 2 Postoperative outcomes

\begin{tabular}{llll}
\hline Outcomes & DXM $(n=52)$ & N-DXM $(n=40)$ & $P$ \\
\hline Pain score on the second day & $3.60 \pm 0.21$ & $4.83 \pm 0.32$ & 0.001 \\
Postoperative hospital stay, days & $6.21 \pm 0.44$ & $6.48 \pm 0.36$ & 0.658 \\
$\begin{array}{l}\text { Postoperative adverse events, } \\
n \text { (\%) }\end{array}$ & & 0.313 \\
$\quad$ Adverse cardiac events & 0 & $3(7.5)$ & \\
$\quad \begin{array}{l}\text { Adverse cerebrovascular } \\
\text { events }\end{array}$ & $1(1.9)$ & 0 & 0.718 \\
3-month follow-up, $n$ (\%) & & & \\
$\quad \begin{array}{l}\text { Type I endoleak } \\
\text { Type II endoleak }\end{array}$ & 0 & $1(2.5)$ & \\
\hline
\end{tabular}

DXM dexamethasone group, $N$-DXM non-dexamethasone group
Table 3 Systemic inflammatory response syndrome evaluation and the peak value of variables during the initial 5 postoperative days

\begin{tabular}{llll}
\hline Variables & DXM $(n=52)$ & N-DXM $(n=40)$ & $P$ \\
\hline SIRS criteria, $n(\%)$ & $20(38.5)$ & $13(32.5)$ & 0.555 \\
2 & $17(32.7)$ & $9(22.5)$ & \\
3 & $3(5.8)$ & $4(10.0)$ & \\
White blood cell, $\times 10^{9} / \mathrm{L}$ & $13.01 \pm 0.58$ & $10.04 \pm 0.61$ & 0.002 \\
Body temperature, ${ }^{\circ} \mathrm{C}$ & $37.67 \pm 0.08$ & $37.92 \pm 0.09$ & 0.040 \\
Heart rate, bpm & $89.06 \pm 1.21$ & $95.95 \pm 1.70$ & 0.001 \\
\hline
\end{tabular}

Bpm beats per minute, DXM dexamethasone group, N-DXM nondexamethasone group, SIRS systemic inflammatory response syndrome

\section{Results}

Patients' characteristics

Between June 2012 and June 2014, a total of 306 consecutive TBADs patients were enrolled in our center. Of 92 were chronic dissections and intervened TEVAR with epidural anesthesia, divided into DXM $(n=52)$ and NDXM $(n=40)$ groups (Fig. 1$)$. The indications for TEVAR included one of the following clinical or anatomical characteristics: malperfusion $(n=28,30.4 \%)$; contained or impending rupture $(n=17,18.5 \%)$; persistent intractable chest/back pain $(n=32,34.8 \%)$; refractory hypertension $(n=15,16.3 \%)$.

Patients' demographics were presented in Table 1. Technical success was achieved in all patients. There were no significant differences between DXM and NDXM groups.

\section{Postoperative outcomes}

No 30-day mortality and incision infection occurred in each group. There was no difference of postoperative hospital stay between DXM and N-DXM groups (6.21 \pm 0.44 days versus $6.48 \pm 0.36$ days, $P=0.658$ ). The proportions of postoperative adverse events were 1.9 and $7.5 \%$ in DXM and N-DXM groups $(P=0.313)$, respectively. The postoperative pain score on the second day was significantly higher in N-DXM group (3.60 \pm 0.21 versus $4.83 \pm 0.32, P=0.001)$. The incidence of endoleak was comparable in the two groups $(1.9 \%$ versus $5.0 \%$, $P=0.718$ ) at 3 -month follow-up point (Table 2).

\section{Systemic inflammatory response syndrome evaluation}

According to the criteria of systemic inflammatory response syndrome, no significant difference of postimplantation syndrome was observed in the two groups (38.5\% versus $32.5 \%, P=0.555)$. The differences of white blood cell, body temperature and heart rate were pronounced in DXM and N-DXM groups judged by the peak values $\left(13.01 \pm 0.58 \times 10^{9} / \mathrm{L}\right.$ versus $10.04 \pm 0.61 \times$ $10^{9} / \mathrm{L}, 37.67 \pm 0.08{ }^{\circ} \mathrm{C}$ versus $37.92 \pm 0.09{ }^{\circ} \mathrm{C}$ and $89.06 \pm$ 


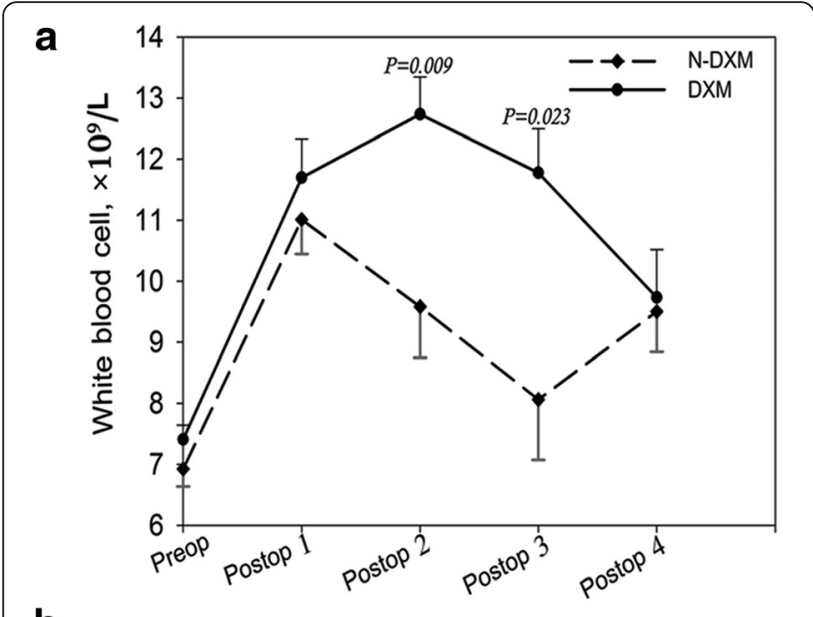

b

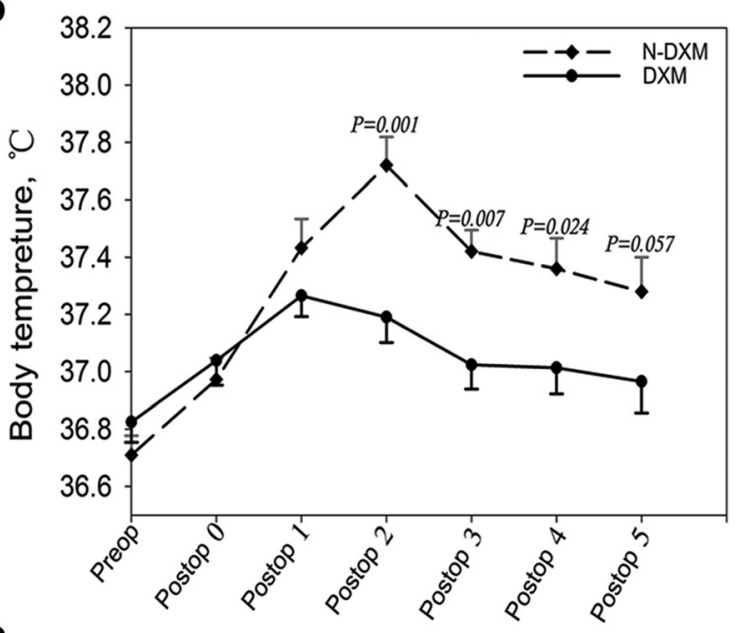

C

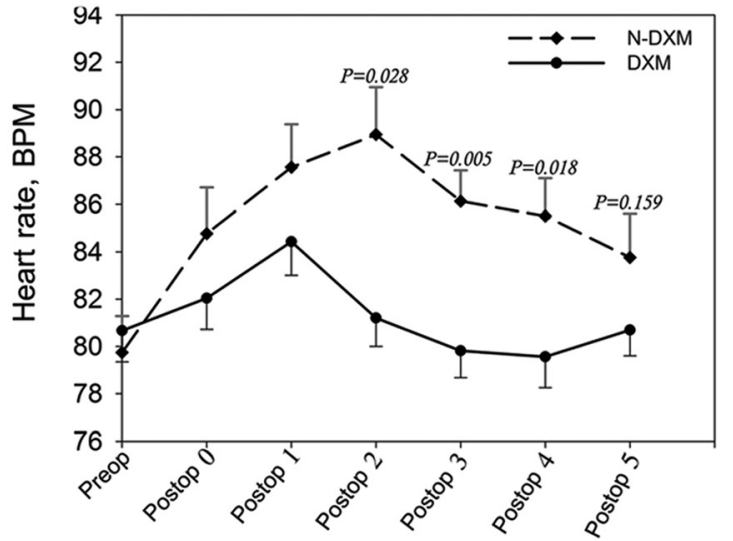

Fig. 2 Curve charts of white blood cell, body temperature and heart rate on the preoperative day and the initial five postoperative days. BPM beat per minute, DXM dexamethasone group, N-DXM nondexamethasone group, Postop postoperative, Preop preoperative

$1.21 \mathrm{bpm}$ versus $95.95 \pm 1.70 \mathrm{bpm}, P=0.002,0.04$ and 0.001 , respectively) (Table 3 ).

The white blood cells in DXM group significantly increased on the second and the third postoperative day $(P=0.009$ and 0.023 respectively) (Fig. 2a). The body temperature and heart rate showed an apparent decline on the second ( $P=0.001$ and 0.028 , respectively), third $(P=0.007$ and 0.005 , respectively) and fourth postoperative days $(P=0.024$ and 0.018 , respectively) in DXM group (Fig. $2 \mathrm{~b}$ and $\mathrm{c}$ ).

\section{The change of false lumen volumes}

No difference of change of false lumen volumes was found between DXM and N-DXM groups $(P=0.862)$ (Fig. 3b). There were no significant differences in the fibrinogen, activated partial thromboplastin time, prothrombin time, platelet and hemoglobin between the two groups at the baseline and peak/valley levels (Table 4).

\section{Discussion}

Many studies have concluded that perioperative glucocorticoids administration has a favorable effect on the prognosis in different lesions [10-12]. To our knowledge, the potential influence of perioperative glucocorticoids administration on the prognosis of aortic dissection after TEVAR has not been reported. In the present study, short-term prophylactic administration of low-dose dexamethasone ( $5 \mathrm{mg} /$ day for 3 days) promoted the recovery of vital signs and alleviated the postoperative pain. However, the efficacy couldn't be able to influence the 30 day mortality, incision infection, coagulation system, and the process of thrombosis in false lumen after chronic TBADs patients underwent TEVAR.

Body temperature and heart rate are two important vital signs, which could provide significant information about physiological condition and predict adverse events [19]. And patients with abnormal vital signs such as persistent fever and tachycardia are always associated with mortality $[19,20]$. Moreover, pain is considered as the fifth vital sign $[21,22]$. Acute postoperative pain might have detrimental effects on the recovery of patients, or even lead to serious morbidity or death [23]. We found that prophylactic administration of dexamethasone could improve the vital signs and alleviate the acute postoperative chest/back pain in the present study.

Although perioperative long-term and high-dose using dexamethasone might increase the risk of surgical incision infection, induce the gastric ulceration and suppress the activity of adrenal gland [13, 24], there was no enough evidence to suggest that the adverse effects was associated with short-term and low-dose administration of glucocorticoids [10-12, 25, 26], which was demonstrated in our results. The transient hyperglycemic response might have no relation with postoperative complications [27, 28]. Nevertheless, the controversies still exist about the type, time, dose, duration and strategy (prophylactic or aggressive) of glucocorticoids using $[7,14,29,30]$. 

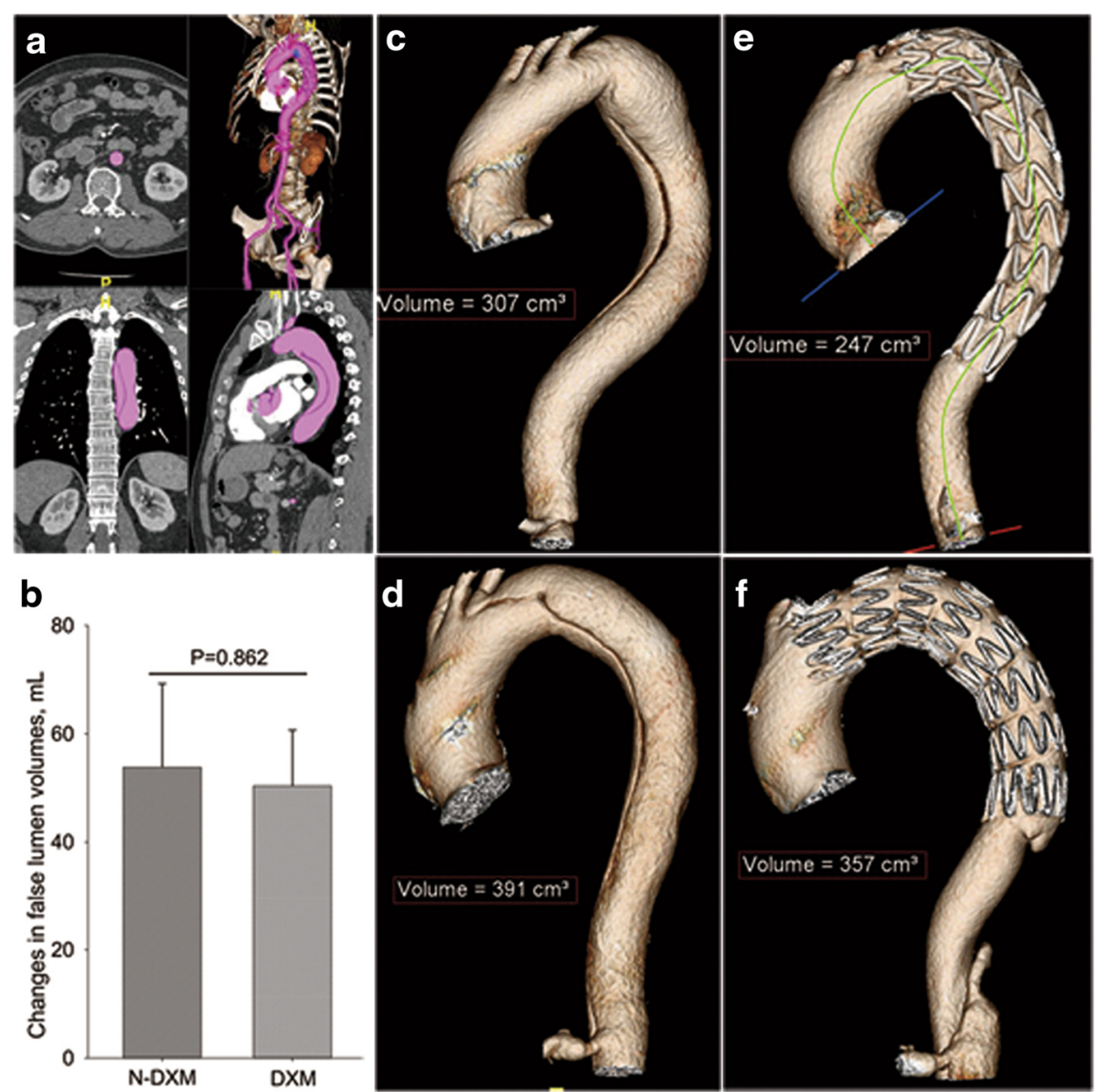

Fig. 3 Luminal volume calculations by the dedicated three-dimensional Aquarius Workstation CT-image processing software. a the process of three-dimensional image reconstruction; $\mathbf{b}$ changes in false lumen volumes in N-DXM and DXM groups; $\mathbf{c}$ and $\mathbf{d}$, preoperative aortic morphology in DXM and N-DXM groups, respectively; e and $\mathbf{f}$ postoperative aortic morphology in DXM and N-DXM groups, respectively. DXM dexamethasone group, N-DXM non-dexamethasone group

The criteria of systemic inflammatory response syndrome have been widely accepted as the diagnostic methods for post-implantation syndrome after endovascular aortic repair [7, 31, 32]. However, the proportions of post-implantation syndrome according to the systemic inflammatory response syndrome criteria were comparable in DXM and N-DXM groups. We also found administration of dexamethasone could increase leukocytosis, and lower the body temperature and heart rate to the normal level, which was regard as a "separation" phenomenon. Therefore, it might be unreasonable to evaluate the severity of post-implantation syndrome based on the systemic inflammatory response syndrome criteria. Previous study had demonstrated that dexamethasone could stimulate the neutrophils released from bone marrow and inhibit its apoptosis, which would provide an explanation for the phenomenon that the leukocyte was significantly higher on the second and third postoperative days in DXM group [33].
Glucocorticoids might increase the activity of coagulation factors in vivo [34, 35]. Perioperative usage of glucocorticoids could not only increase the activity of factor VII, VIII and XI, but also enlarge the ratio of plasminogen activator inhibitor-1 and tissue-type plasminogen activator [36, 37]. The influence of glucocorticoids on the thrombosed process of false lumen was still obscure. However, the effects mentioned above were not observed in the present study, which might attribute to the intraoperative application of heparin and persistent blood flow into the false lumen from the re-entry tear of dissection [38].

\section{Limitations}

There are a few limitations in our study. This is a retrospective single-center study and sample size is relatively small in each group. Another important limitation was the lack of observation of the influence on inflammatory response following TEVAR due to the timing, duration and 
Table 4 Variables difference for new-onset thrombosis in false lumen

\begin{tabular}{|c|c|c|c|}
\hline Variables & DXM $(n=52)$ & $\mathrm{N}-\mathrm{DXM}(n=40)$ & $P$ \\
\hline \multicolumn{4}{|l|}{ Fibrinogen, $\mathrm{g} / \mathrm{L}$} \\
\hline Baseline & $4.86 \pm 0.26$ & $4.29 \pm 0.28$ & 0.138 \\
\hline Peak value & $4.44 \pm 0.16$ & $4.10 \pm 0.20$ & 0.186 \\
\hline \multicolumn{4}{|l|}{ APTT, second } \\
\hline Baseline & $35.02 \pm 0.56$ & $33.88 \pm 0.77$ & 0.225 \\
\hline Peak value & $41.03 \pm 2.52$ & $42.36 \pm 3.91$ & 0.766 \\
\hline \multicolumn{4}{|c|}{ Prothrombin time, second } \\
\hline Baseline & $13.66 \pm 0.22$ & $13.30 \pm 0.12$ & 0.193 \\
\hline Peak value & $13.83 \pm 0.17$ & $13.78 \pm 0.16$ & 0.834 \\
\hline \multicolumn{4}{|l|}{ Platelet, $\times 10^{9} / \mathrm{L}$} \\
\hline Baseline & $194.81 \pm 10.67$ & $219.65 \pm 13.35$ & 0.145 \\
\hline Valley value & $181.31 \pm 10.97$ & $178.00 \pm 10.19$ & 0.838 \\
\hline \multicolumn{4}{|c|}{ Hemoglobin, g/L } \\
\hline Baseline & $126.40 \pm 2.65$ & $131.15 \pm 2.14$ & 0.186 \\
\hline Valley value & $115.12 \pm 2.49$ & $115.47 \pm 3.02$ & 0.931 \\
\hline
\end{tabular}

APTT activated partial thromboplastin time, DXM dexamethasone group, $\mathrm{N}$ DXM non-dexamethasone group

different doses of glucocorticoids administration. Thus, we could not further explain the mechanism of change in clinical status in our study. Based on the above understanding, a prospective, open, randomized, placebocontrolled trial has been registered (NCT02523300), which will be helpful to overcome the limitations, and be warranted before prophylactic administration of glucocorticoids after TEVAR procedure could be recommended in the clinical work.

\section{Conclusions}

Although postoperative short-term prophylactic administration of low-dose glucocorticoids do not influences mortality, incision infection or the change in false lumen volumes after TEVAR procedure for chronic TBADs, it significantly promotes the recovery of vital signs and alleviates the postoperative pain. It's worth considered to redefine the post-implantation syndrome with standardized diagnostic criteria, probably introducing determinations of some inflammatory biomarkers.

\section{Additional file}

Additional file 1: Table S1. Detailed information of TEVAR. (DOC $35 \mathrm{~kb}$ )

\section{Abbreviations}

CTA: computed tomography angiography; DXM: dexamethasone group; N-DXM: non-dexamethasone group; TBAD: type B aortic dissection;

TEVAR: thoracic endovascular aortic repair.

\section{Competing interests}

The authors declare that they have no competing interests.

\section{Authors' contributions}

MTW and LZ participated in conception and design, data collection, analysis and interpretation, statistical analysis, and wrote the manuscript. ZPJ, JZ and JMB participated in conception and design, data collection, obtained funding, provided critical revision of the article, and take overall responsibility for this study. ZQZ and QSL participated in data collection, analysis and interpretation, statistical analysis, and provided critical revision of the article. RF and CS participated in data collection, analysis and interpretation, and provided critical revision of the article. All authors read and approved the final manuscript.

\section{Acknowledgements}

Zaiping Jing, MD, PhD, was supported by National Natural Science Foundation of China (81330034); Jian Zhou, MD, was supported by National Natural Science Foundation of China (81273522, 81173072); Junmin Bao, MD, was supported by the Key Project of Basic Research in Shanghai (12JC1410802).

\section{Author details}

${ }^{1}$ Department of Vascular Surgery, Changhai Hospital, Second Military Medical University, 168 Changhai Road, Shanghai 200433, China. ${ }^{2}$ Department of Vascular Surgery, General Hospital of Jinan Military Command of Chinese PLA, Jinan, China.

Received: 9 September 2015 Accepted: 19 March 2016

Published online: 25 March 2016

\section{References}

1. Sachs T, Pomposelli F, Hagberg R, Hamdan A, Wyers M, Giles K, et al. Open and endovascular repair of type $b$ aortic dissection in the nationwide inpatient sample. J Vasc Surg. 2010;52:860-6.

2. Luebke T, Brunkwall J. Outcome of patients with open and endovascular repair in acute complicated type b aortic dissection: a systematic review and meta-analysis of case series and comparative studies. J Cardiovasc Surg (Torino). 2010;51:613-32.

3. Hanna JM, Andersen ND, Ganapathi AM, McCann RL, Hughes GC. Five-year results for endovascular repair of acute complicated type $b$ aortic dissection. J Vasc Surg. 2014;59:96-106.

4. Nienaber CA, Rousseau H, Eggebrecht $H$, Kische S, Fattori R, Rehders TC, et al. Randomized comparison of strategies for type $b$ aortic dissection: the investigation of stent grafts in aortic dissection (instead) trial. Circulation. 2009;120:2519-28.

5. Voûte MT1, Bastos Gonçalves FM, van de Luijtgaarden KM, Klein Nulent CG, Hoeks SE, Stolker RJ, et al. Stent graft composition plays a material role in the postimplantation syndrome. J Vasc Surg. 2012;56:1503-9.

6. Videm V, Ødegård A, Myhre HO. lohexol-induced neutrophil myeloperoxidase release and activation upon contact with vascular stentgraft material: a mechanism contributing to the postimplantation syndrome? J Endovasc Ther. 2003;10:958-67.

7. Arnaoutoglou E, Papas N, Milionis H, Kouvelos G, Koulouras V, Matsagkas Ml. Post-implantation syndrome after endovascular repair of aortic aneurysms: need for postdischarge surveillance. Interac Cardiovasc Thorac Surg. 2010;11:449-54.

8. Rhen T, Cidlowski JA. Antiinflammatory action of glucocorticoids - new mechanisms for old drugs. N Engl J Med. 2005;353:1711-23.

9. Owens CD, Gasper WJ, Walker JP, Alley HF, Conte MS, Grenon SM. Safety and feasibility of adjunctive dexamethasone infusion into the adventitia of the femoropopliteal artery following endovascular revascularization. J Vasc Surg. 2014;59:1016-24.

10. Orci LA, Toso C, Mentha G, Morel P, Majno PE. Systematic review and metaanalysis of the effect of perioperative steroids on ischaemia-reperfusion injury and surgical stress response in patients undergoing liver resection. $\mathrm{Br}$ J Surg. 2013;100:600-9.

11. Srinivasa S, Kahokehr AA, Yu TC, Hill AG. Preoperative glucocorticoid use in major abdominal surgery: systematic review and meta-analysis of randomized trials. Ann Surg. 2011;254:183-91.

12. Lunn TH, Kehlet H. Perioperative glucocorticoids in hip and knee surgery benefit vs. Harm? A review of randomized clinical trials. Acta Anaesthesiol Scand. 2013;57:823-34.

13. Schäcke H, Döcke W-D, Asadullah K. Mechanisms involved in the side effects of glucocorticoids. Pharmacol Ther. 2002;96:23-43. 
14. Morikage N, Esato K, Zenpo N, Fujioka K, Takenaka H. Is endovascular treatment of abdominal aortic aneurysms less invasive regarding the biological responses? Surg Today. 2000;30:142-6.

15. Eggebrecht $H$, Mehta RH, Metozounve H, Huptas S, Herold U, Jakob HG, et al. Clinical implications of systemic inflammatory response syndrome following thoracic aortic stent-graft placement. J Endovasc Ther. 2008; 15:135-43.

16. Ker CR, Ho MC, Huang JW, Hsieh CC, Chen HM. Pyrexia of postimplantation syndrome for patients undergoing (thoracic) endovascular aortic repair. Thorac Cardiovasc Surg. 2015;63:126-33.

17. Erbel R, Aboyans V, Boileau C, Bossone E, Bartolomeo RD, Eggebrecht $\mathrm{H}$, et al. 2014 ESC guidelines on the diagnosis and treatment of aortic diseases: document covering acute and chronic aortic diseases of the thoracic and abdominal aorta of the adult. The Task Force for the Diagnosis and Treatment of Aortic Diseases of the European Society of Cardiology (ESC). Eur Heart J. 2014;35:2873-926.

18. Bijur PE, Silver W, Gallagher EJ. Reliability of the visual analog scale for measurement of acute pain. Acad Emerg Med. 2001;8:1153-7.

19. Chen J, Hillman K, Bellomo R, Flabouris A, Finfer S, Cretikos M. The impact of introducing medical emergency team system on the documentations of vital signs. Resuscitation. 2009;80:35-43.

20. Harrison GA, Jacques T, McLaws M-L, Kilborn G. Combinations of early signs of critical illness predict in-hospital death - the soccer study (signs of critical conditions and emergency responses). Resuscitation. 2006;71: 327-34.

21. Rousseau P. Pain as the fifth vital sign. Arch Surg. 2008;143:98.

22. Morone NE, Weiner DK. Pain as the fifth vital sign: exposing the vital need for pain education. Clin Ther. 2013;35:1728-32.

23. Oderda G. Challenges in the management of acute postsurgical pain. Pharmacotherapy. 2012;32:6S-11S.

24. Hengge UR, Ruzicka T, Schwartz RA, Cork MJ. Adverse effects of topical glucocorticosteroids. J Am Acad Dermatol. 2006;54:1-15.

25. Dieleman JM, Nierich AP, Rosseel PM, van der Maaten JM, Hofland J, Diephuis JC, et al. Intraoperative high-dose dexamethasone for cardiac surgery: a randomized controlled trial. JAMA. 2012;308:1761-7.

26. Wang AS, Armstrong EJ, Armstrong AW. Corticosteroids and wound healing: clinical considerations in the perioperative period. Am J Surg. 2013:206:410-7.

27. Abdelmalak BB, Bonilla AM, Yang D, Chowdary HT, Gottlieb A, Lyden SP, et al. The hyperglycemic response to major noncardiac surgery and the added effect of steroid administration in patients with and without diabetes. Anesth Analg. 2013;116:1116-22.

28. de la Motte L, Kehlet H, Vogt K, Nielsen CH, Groenvall JB, Nielsen HB, et al. Preoperative methylprednisolone enhances recovery after endovascular aortic repair: a randomized, double-blind, placebo-controlled clinical trial. Ann Surg. 2014;260:540-8,

29. Gerasimidis T, Sfyroeras G, Trellopoulos G, Skoura L, Papazoglou K Konstantinidis $\mathrm{K}$, et al. Impact of endograft material on the inflammatory response after elective endovascular abdominal aortic aneurysm repair. Angiology. 2005;56:743-53

30. Gabriel EA, Locali RF, Romano CC, Duarte AJ, Palma JH, Buffolo E. Analysis of the inflammatory response in endovascular treatment of aortic aneurysms. Eur J Cardiothorac Surg. 2007;31:406-12.

31. De La Motte L, Vogt K, Panduro Jensen L, Groenvall J, Kehlet H, Veith Schroeder $\mathrm{T}$, et al. Incidence of systemic inflammatory response syndrome after endovascular aortic repair. J Cardiovasc Surg (Torino). 2011;52:73-9.

32. Norwood MG, Bown MJ, Lloyd G, Bell PR, Sayers RD. The clinical value of the systemic inflammatory response syndrome (SIRS) in abdominal aortic aneurysm repair. Eur J Vasc Endovasc Surg. 2004;27:292-8.

33. Weng M, Sun Z, Miao C. Corticosteroid induce leukocytosis during the pain management. Pain Med. 2014;15:1645-6.

34. Brotman DJ, Girod JP, Posch A, Jani JT, Patel JV, Gupta M, et al. Effects of short-term glucocorticoids on hemostatic factors in healthy volunteers. Thromb Res. 2006;118:247-52.

35. Johannesdottir SA, Horváth-Puhó E, Dekkers OM, Cannegieter SC, Jørgensen $\mathrm{JO}$, Ehrenstein $\mathrm{V}$, et al. Use of glucocorticoids and risk of venous thromboembolism: a nationwide population-based case-control study. JAMA Intern Med. 2013;173:743-52.

36. Squizzato A, Gerdes VE, Ageno W, Buller HR. The coagulation system in endocrine disorders: a narrative review. Intern Emerg Med. 2007;2:76-83.
37. van Zaane B, Nur E, Squizzato A, Gerdes VE, Büller HR, Dekkers OM, et al. Systematic review on the effect of glucocorticoid use on procoagulant, anti-coagulant and fibrinolytic factors. J Thromb Haemost. 2010;8:2483-93.

38. Conrad MF, Crawford RS, Kwolek CJ, Brewster DC, Brady TJ, Cambria RP. Aortic remodeling after endovascular repair of acute complicated type b aortic dissection. J Vasc Surg. 2009;50:510-7.

\section{Submit your next manuscript to BioMed Central and we will help you at every step:}

- We accept pre-submission inquiries

- Our selector tool helps you to find the most relevant journal

- We provide round the clock customer support

- Convenient online submission

- Thorough peer review

- Inclusion in PubMed and all major indexing services

- Maximum visibility for your research

Submit your manuscript at www.biomedcentral.com/submit
C Biomed Central 